\title{
Two Species Commensalism Model with Harvesting by Homotopy Analysis Method
}

\author{
J Govardhan Reddy, B Seetha Rambabu, N L Mohan
}

\begin{abstract}
In the present investigation a two species commensalism model was taken up for detailed analytical study in which commensal species was harvested at a rate proportional to its strength. The system under investigation was represented by a coupled non linear ordinary differential equations. The series solution of the non-linear system was approximated by Homotopy Analysis Method.
\end{abstract}

Keywords: Commensalism, Harvesting, HAM, h-Curves, t-Curves, MATLAB.

\section{INTRODUCTION}

Commensalism, in science, a connection between people of two species wherein one animal categories gets sustenance or different advantages from the other without either hurting or profiting the last mentioned. The commensal-the species that advantages from the affiliation-may get supplements, sanctuary, backing, or motion from the host species, which is unaffected. The commensal connection is regularly between a bigger host and a littler commensal. The host creature is basically unaltered by the association, while the commensal species may indicate extraordinary morphological adjustment. This relationship can be appeared differently in relation to mutualism, in which the two species advantage.

Extraordinary compared to other known instances of a commensal is the remora (family Echineidae) that rides appended to sharks and different fishes. Remoras have developed on the highest point of their heads a level oval sucking circle structure that holds fast to the groups of their hosts. The two remoras and pilot fishesfeed on the remains of their hosts' suppers. Different instances of commensals incorporate feathered creature species, for example, the extraordinary egret (Ardea alba), that feed on creepy crawlies turned up by touching warm blooded creatures or on soilorganisms worked up by furrowing. Different gnawing lice, insects, and mite fliesare commensals in that they feed innocuously on the quills of feathered creatures and on sloughed-off pieces of skin from well evolved creatures.

Revised Version Manuscript Received on 16 September, 2019.

Govardhan Reddy. J., Assistant Professor, Vidya Jyothi Institute of Technology, Hyderabad-500075, Telangana, India, goverdhanreddy.javini@gmail.com

Dr. Sitarambabu. B., Professor of Mathematics, Vidya Jyothi Institute of Technology, Hyderabad-500075, Telangana, India, sitarambabu.b@gmail.com

Dr. N. L. Mohan., Rtd. Professor, Osmania University, Hyderabad, Telangana, India, nl_mohan@yahoo.com

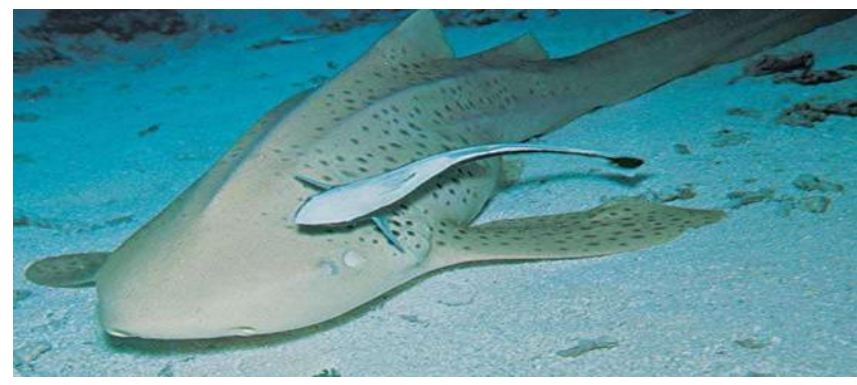

Fig 1. Example

In this section a two animal varieties Commensalism model with constrained assets for both the species was taken up for scientific examination. The model is spoken to by coupled non-straight standard differential conditions. The arrangement of the non-straight framework is approximated by Homotopy Analysis Method. Symbioses are an expansive class of connections among creatures commensalism includes one living being is profited by another with no positive or negative advantage for itself.

Ever since research in the discipline of theoretical ecology was initiated by Lotka[1] and Voltera [2]. Later on many mathematicians and ecologists contributed to the growth of this area as reported in the treaties of Meyer [3], Cushing [4] and Kapur [5 \& 6]. B. Ravindra Redyy. Et al. [7] discussed the Global Stability of Two Mutually Interacting Species with Limited Resources for both the Species. Lakshmi Narayan et al. [8] investigated prey-predator ecological models with a partial cover for the prey and alternative food for predator and Time Delay. Paparao. A. V. et al. [9] studied three species ecological models with time delay. Kondala Rao. K. et Al. [12, 13 \& 14] discussed "Stability analysis of dynamical system with ammensal relationship between three species with limited resources". K. Shivareddy. et al.[10] investigated the three species Eco System Consisting Prey and two prediator. Lakshmi Narayan. K. et al.[11] discussed 'Time Delayed Commensallyism Model. Xiangdong Xiea et al [15] identified Dynamic behaviors of two species amensalism model with a cover for the first species. Liang Zhao. et al, [16] investigated Dynamic Behavior of a Commensalism Model with Nonmonotonic Functional Response and Density-Dependent Birth Rates.

\section{Mathematical MOdeL}

The governing equations of the system are as follows

$$
\begin{aligned}
& \frac{d x}{d t}=a_{1}(1-k) x(t)-\alpha_{11} x^{2}(t)+\alpha_{12} x(t) y(t) \\
& \frac{d y}{d t}=a_{2} y(t)-\alpha_{22} y^{2}(t)
\end{aligned}
$$




\section{A. Solutions as Polynomials of the model (2.1) by HAM}

Consider the nonlinear differential equation (2.1) with initial conditions $\mathrm{x}_{0}$ and $\mathrm{y}_{0}$. The solutions $\mathrm{x}(\mathrm{t}), \mathrm{y}(\mathrm{t})$ can be expressed by following set of base functions in the form

$$
x(t)=\sum_{m=1}^{+\infty} a_{m} t^{m}, y(t)=\sum_{m=1}^{+\infty} b_{m} t^{m}
$$

Where $\mathrm{a}_{\mathrm{m}}, \mathrm{b}_{\mathrm{m}}$ are coefficients to be determined.

Choose the linear operator and non-linear operators are denoted as follows.

$L_{1}[x(t ; p)]=\frac{d x(t ; p)}{d t}, L_{1}[y(t ; p)]=\frac{d y(t ; p)}{d t}$

$L_{1}[x(t, p)]=\frac{d x(t ; p)}{d t}-a_{1}(1-k) x(t ; p)+\alpha_{11} x^{2}(t ; p)-\alpha_{12} x(t ; p) .2(t ; p)$

$L_{1}[y(t, p)]=\frac{d y(t ; p)}{d t}-a_{2} y(t ; p)+\alpha_{22} y^{2}(t ; p)$

The zero order deformation equation can be constructed using the above definition.

$(1-p) L_{1}\left[x(t ; p)-x_{0}(t)\right]=p h_{1} N[x, y]$,

$(1-p) L_{2}\left[y(t ; p)-y_{0}(t)\right]=p h_{2} N[x, y]$,

When $\mathrm{p}=0$ and $\mathrm{p}=1$, from the zero-deformation equations one has,

$$
\begin{aligned}
& x(t ; 0)=x_{0}(t) \quad x(t ; 1)=x(t) \\
& y(t ; 0)=y_{0}(t) \quad y(t ; 1)=y(t)
\end{aligned}
$$

And expanding $\mathrm{x}(\mathrm{t} ; \mathrm{p})$ and $\mathrm{y}(\mathrm{t} ; \mathrm{p})$ in Taylors series, with respect to embedding parameter $\mathrm{p}$, one obtains

$$
\begin{aligned}
& x(t ; p)=x_{0}(t)+\sum_{m=1}^{+\infty} x_{m}(t) p^{m} \\
& y(t ; p)=y_{0}(t)+\sum_{m=1}^{+\infty} y_{m}(t) p^{m} \\
& x_{m}(t)=\left.\frac{1}{m !} \frac{d^{m} x(t ; p)}{d p^{m}}\right|_{p=0} y_{m}(t)=\left.\frac{1}{m !} \frac{d^{m} y(t ; p)}{d p^{m}}\right|_{p=0} \\
& p=1\left\{\begin{array}{l}
x_{m}(t)=x_{0}(t)+\sum_{m=1}^{+\infty} x_{m}(t) \\
y_{m}(t)=y_{0}(t)+\sum_{m=1}^{+\infty} y_{m}(t)
\end{array}\right.
\end{aligned}
$$

Define the vector

$$
\vec{x}_{m}=\left[x_{0}(t), x_{1}(t), \ldots . x_{m}(t)\right]
$$

$$
\vec{y}_{m}=\left[y_{0}(t), y_{1}(t), \ldots . y_{m}(t)\right]
$$

And apply the procedure stated before. The following $\mathrm{m}^{\text {th }}$-order deformation Equations will be achieved.

$L_{1}\left[x_{m}(t)-\chi_{m} x_{m-1}(t)\right]=\bar{h}_{1} H_{1}(t) R_{1 m}\left(\vec{x}_{m-1}, \vec{y}_{m-1}\right)$,

$L_{1}\left[y_{m}(t)-\chi_{m} y_{m-1}(t)\right]=\bar{h}_{2} H_{2}(t) R_{2 m}\left(\vec{x}_{m-1}, \vec{y}_{m-1}\right)$,

Let us consider $H_{1}(t)=H_{2}(t)=1$ and the initial conditions $x_{0}(t)=x(t=0)=x_{0} \quad y_{0}(t)=y(t=0)=y_{0}$ in above equations

$$
\begin{aligned}
& R_{1 m}\left(x_{m-1}, y_{m-1}\right)=\frac{1}{(m-1) !} \frac{d^{m-1}}{d p^{m-1}} N[x(t, p)]=\frac{d}{d t} x_{m-1}(t)-a_{1}(1-k) x_{m-1}+\alpha_{11} \sum_{n=1}^{m} x_{n}(t) x_{m-n-1}(t) \\
& -\alpha_{12} \sum_{n=0}^{m-1} x_{n}(t) y_{m-n-1}(t) \\
& R_{2 m}\left(x_{m-1}, y_{m-1}\right)=\frac{1}{(m-1) !} \frac{d^{m-1}}{d p^{m-1}} N[y(t, p)]=\frac{d}{d t} y_{m-1}(t)-a_{2} y_{m-1}+\alpha_{22} \sum_{n=1}^{m} y_{n}(t) y_{m-n-1}(t)
\end{aligned}
$$

The solution of $\mathrm{m}^{\text {th }}$ order deformation equation is given by for $\mathrm{m} \geq 1$

$$
\begin{aligned}
& x_{1, m}(t)=\chi_{m} x_{1, m-1}(t)+h L^{-1}\left[R_{1, m}\left(x_{m-1}, y_{m-1}\right)\right] \\
& y_{1, m}(t)=\chi_{m} y_{1, m-1}(t)+h L^{-1}\left[R_{2, m}\left(x_{m-1}, y_{m-1}\right)\right] \\
& \text { and } \chi_{m}=\left\{\begin{array}{l}
0, m \leq 1, \\
1, m>1 .
\end{array}\right.
\end{aligned}
$$

The analytic solution of the model (2.1) using polynomial base function can be expressed as

$$
x(t)=\sum_{m=1}^{+\infty} a_{m}(h) t^{m}, y(t)=\sum_{m=1}^{+\infty} b_{m}(h) t^{m}
$$

First approximation for the model (2.1) is given by

$$
\begin{aligned}
& L_{1}\left(x_{1}(t)-\chi_{1} x_{0}(t)\right)=h\left[-a_{1}(1-k) x_{0}(t)+\alpha_{11} x_{0}^{2}(t)-\alpha_{12} x_{0}(t) y_{0}(t)\right] \\
& x_{1}(t)=h\left[-a_{1}(1-k) x_{0}+\alpha_{11} x_{0}^{2}-\alpha_{12} x_{0} y_{0}\right] t \\
& x_{1}(t)=h k_{1} t \\
& L_{1}\left(y_{1}(t)-\chi_{1} y_{0}(t)\right)=h\left[-a_{2} y_{0}(t)+\alpha_{22} y_{0}^{2}(t)\right] \\
& y_{1}(t)=h\left[-a_{2} y_{0}+\alpha_{22} y_{0}^{2}\right] t \\
& y_{1}(t)=h k_{2} t
\end{aligned}
$$

where

$k_{1}=\left[-a_{1}(1-k) x_{0}+\alpha_{11} x_{0}^{2}-\alpha_{12} x_{0} y_{0}\right]$

(2.A.16)

$k_{2}=\left[-a_{2} y_{0}+\alpha_{22} y_{0}^{2}\right]$

The following second approximations for the system (2.1) is $L_{1}\left(x_{2}(t)-\chi_{2} x_{1}(t)\right)=h\left[\frac{d}{d t} x_{1}(t)-a_{1}(1-k) x_{1}(t)+\alpha_{11} \sum_{n=0}^{1} x_{n}(t) x_{1-n}(t)-\alpha_{12} \sum_{n=0}^{1} x_{n}(t) y_{1-n}(t)\right]$ $x_{2}(t)=\left(h k_{1} t+h^{2} k_{1} t+l_{1} h^{2} t^{2}\right)$

$L_{1}\left(y_{2}(t)-\chi_{2} y_{1}(t)\right)=h\left[\frac{d}{d t} y_{1}(t)-a_{2} y_{1}(t)+\alpha_{22} \sum_{n=0}^{1} y_{n}(t) y_{1-n}(t)\right]$

$y_{2}(t)=\left(h k_{2} t+h^{2} k_{2} t+l_{2} h^{2} t^{2}\right)$

where

$l_{1}=\left[\frac{-1}{2} a_{1}(1-k) k_{1}+x_{0} \alpha_{11} k_{1}-\frac{1}{2} y_{0} \alpha_{12} k_{1}-\frac{1}{2} x_{0} \alpha_{12} k_{2}\right]$

$$
\text { (2.A.17) }
$$

$l_{2}=\left[\frac{-1}{2} a_{2} k_{2}+y_{0} \alpha_{22} k_{2}\right]$

The third approximations for system (2.1) is given by $L_{1}\left(x_{3}(t)-\chi_{3} x_{2}(t)\right)=h\left[\frac{d}{d t} x_{2}(t)-a_{1}(1-k) x_{2}(t)+\alpha_{11} \sum_{n=0}^{2} x_{n}(t) x_{1-n}(t)-\alpha_{12} \sum_{n=0}^{2} x_{n}(t) y_{1-n}(t)\right]$ $x_{3}(t)=h k_{1} t+2 h^{2} k_{1} t+2 l_{1} h^{2} t^{2}+h^{3} k_{1} t+2 l_{1} h^{3} t^{2}+m_{1} h^{3} t^{3}$ $L_{1}\left(y_{3}(t)-\chi_{3} y_{2}(t)\right)=h\left[\frac{d}{d t} y_{2}(t)-a_{2} y_{2}(t)+\alpha_{22} \sum_{n=0}^{2} y_{n}(t) y_{1-n}(t)\right]$ $y_{3}(t)=h k_{2} t+2 h^{2} k_{2} t+2 l_{2} h^{2} t^{2}+h^{3} k_{2} t+2 l_{2} h^{3} t^{2}+m_{2} h^{3} t^{3}$ where 
$m_{1}=\left[\frac{-1}{3} a_{1}(1-k) l_{1}+\frac{2}{3} x_{0} \alpha_{11} l_{1}+\frac{1}{3} \alpha_{11} k_{1}^{2}-\frac{1}{3} y_{0} \alpha_{12} l_{1}-\frac{1}{3} x_{0} \alpha_{12} l_{2}-\frac{1}{3} \alpha_{12} k_{1} k_{2}\right]$

(2.A.18)

$m_{2}=\left[\frac{-1}{3} a_{2} l_{2}+\frac{2}{3} y_{0} \alpha_{22} l_{2}+\frac{1}{3} \alpha_{22} k_{2}^{2}\right]$

The two terms approximation to the solution will be considered as

$$
\begin{aligned}
& x(t) \approx x_{0}+x_{1}(t)+x_{2}(t) \\
& y(t) \approx y_{0}+y_{1}(t)+y_{2}(t) \\
& x(t) \approx x_{0}+2 k_{1} h t+k_{1} h^{2} t+l_{1} h^{2} t^{2} \\
& y(t) \approx y_{0}+2 k_{2} h t+k_{2} h^{2} t+l_{2} h^{2} t^{2}
\end{aligned}
$$

The three terms approximation to the solution will be considered as

$$
\begin{aligned}
& x(t) \approx x_{0}+x_{1}(t)+x_{2}(t)+x_{3}(t) \\
& y(t) \approx y_{0}+y_{1}(t)+y_{2}(t)+y_{3}(t) \\
& x(t) \approx x_{0}+3 h k_{1} t+3 k_{1} h^{2} t+3 l_{1} h^{2} t^{2}+k_{1} h^{3} t+2 l_{1} h^{3} t^{2}+m_{1} h^{3} t^{3} \\
& y(t) \approx y_{0}+3 h k_{2} t+3 k_{2} h^{2} t+3 l_{2} h^{2} t^{2}+k_{2} h^{3} t+2 l_{2} h^{3} t^{2}+m_{2} h^{3} t^{3}
\end{aligned}
$$

\section{B. HAM Solutions as Polynomial function of the model} (2.1) for different auxiliary parameter $h$, (for $i=1,2)$ :

By choosing the different auxiliary parameter values of $\mathrm{h}_{i}(i=1,2)$, with initial conditions, linear operator are described by equations (2.A.2) to (2.A.4)

The solution of $\mathrm{m}^{\text {th }}$ order deformation equation is given by for $\mathrm{m} \geq 1$

$$
\begin{aligned}
& x_{1, m}(t)=\chi_{m} x_{1, m-1}(t)+h_{1} L^{-1}\left[R_{1, m}\left(x_{1, m-1}, y_{1, m-1}\right)\right] \\
& y_{1, m}(t)=\chi_{m} y_{1, m-1}(t)+h_{2} L^{-1}\left[R_{2, m}\left(x_{1, m-1}, y_{1, m-1}\right)\right] \mathrm{by} \\
& \text { and } \chi_{m}=\left\{\begin{array}{l}
0, m \leq 1, \\
1, m>1 .
\end{array}\right.
\end{aligned}
$$

The analytic solution of the model (2.1) is expressed as

$$
x(t)=\sum_{m=1}^{+\infty} a_{m} t^{m}, y(t)=\sum_{m=1}^{+\infty} b_{m} t^{m}
$$

First approximation for the model (2.1) is given by

$$
\begin{aligned}
& L_{1}\left(x_{1}(t)-\chi_{1} x_{0}(t)\right)=h_{1}\left[-a_{1}(1-k) x_{0}(t)+\alpha_{11} x_{0}^{2}(t)-\alpha_{12} x_{0}(t) y_{0}(t)\right] \\
& x_{1}(t)=h_{1}\left[-a_{1}(1-k) x_{0}+\alpha_{11} x_{0}^{2}-\alpha_{12} x_{0} y_{0}\right] t \\
& L_{1}\left(y_{1}(t)-\chi_{1} y_{0}(t)\right)=h_{2}\left[-a_{2} y_{0}(t)+\alpha_{22} y_{0}^{2}(t)\right] \\
& y_{1}(t)=h_{2}\left[-a_{2} y_{0}+\alpha_{22} y_{0}^{2}\right] t
\end{aligned}
$$

The following second approximations for the system (2.1) is given by

$$
\begin{aligned}
& \begin{array}{c}
L_{1}\left(x_{2}(t)-\chi_{2} x_{1}(t)\right)=h_{1}\left[\frac{d}{d t} x_{1}(t)-a_{1}(1-k) x_{1}(t)+\alpha_{11} \sum_{n=0}^{1} x_{n}(t) x_{1-n}(t)-\alpha_{12} \sum_{n=0}^{1} x_{n}(t) y_{1-n}\right. \\
x_{2}(t)=\left(h_{1}+h_{1}^{2}\right)\left[-a_{1}(1-k) x_{0}+\alpha_{11} x_{0}^{2}-\alpha_{12} x_{0} y_{0}\right] t \\
+\frac{h_{1} x_{0}}{2}\left[\begin{array}{c}
h_{1}\left(-a_{1}(1-k)+\alpha_{11} x_{0}-\alpha_{12} y_{0}\right)\left(-a_{1}(1-k)+2 \alpha_{11} x_{0}-\alpha_{12} y_{0}\right) \\
-h_{2} \alpha_{12}\left(-a_{2} y_{0}(t)+\alpha_{22} y_{0}^{2}(t)\right)
\end{array}\right. \\
L_{1}\left(y_{2}(t)-\chi_{2} y_{1}(t)\right)=h_{2}\left[\frac{d}{d t} y_{1}(t)-a_{2} y_{1}(t)+\alpha_{22} \sum_{n=0}^{1} y_{n}(t) y_{1-n}(t)\right] \\
y_{2}(t)=\left(h_{2}+h_{2}^{2}\right)\left[-a_{2} y_{0}+\alpha_{22} y_{0}^{2}\right] t+\frac{h_{2}^{2} y_{0}}{2}\left(a_{2}^{2}-3 a_{2} \alpha_{22} y_{0}+2 \alpha_{22}^{2} y_{0}^{2}\right) \frac{t^{2}}{2}(2 . B .4)
\end{array}
\end{aligned}
$$$$
\begin{aligned}
& \begin{aligned}
x_{3}(t)=\left(1+h_{1}\right)\left(h_{1}+h_{1}^{2}\right) k_{1} t \\
+\left[\begin{array}{l}
\left.-a_{1}(1-k) h_{1}\left(h_{1}+h_{1}^{2}\right) k_{1}+2 \alpha_{11} x_{0}\left(h_{1}+h_{1}^{2}\right) k_{1} h_{1}-h_{1} \alpha_{12} x_{0} k_{3}\right] \\
\left.-h_{1} \alpha_{12} y_{0}\left(h_{1}+h_{1}^{2}\right) k_{1}\right)
\end{array}\right] \frac{t^{2}}{2} \\
+\left[\begin{array}{l}
\left.h_{1}\left(1+h_{1}\right) k_{2}-\frac{1}{2} a_{1}(1-k) h_{1}^{2} k_{2}+h_{1} \alpha_{11} x_{0} k_{2}+\frac{1}{2} \alpha_{11} h_{1}^{3} k_{1}^{2}\right] \\
-\frac{1}{2} \alpha_{12} h_{1} x_{0} k_{4}-\frac{1}{2}\left(\frac{\alpha_{12} h_{1}^{2} h_{2}}{\left(h_{2}+h_{2}^{2}\right)} k_{1} k_{3}+\frac{h_{1}}{2} \alpha_{12} y_{0} k_{2}\right)
\end{array}\right] \frac{t^{3}}{3} \\
L_{1}\left(y_{3}(t)-\chi_{3} y_{2}(t)\right)=h_{2}\left[\frac{d}{d t} y_{2}(t)-a_{2} y_{2}(t)+\alpha_{22} \sum_{n=0}^{2} y_{n}(t) y_{2-n}(t)\right] \\
y_{3}(t)=\left(1+h_{2}\right) k_{3} t+\left[\left(1+h_{2}\right) k_{4}-a_{2} h_{2} k_{3}+2 h_{2} k_{3} \alpha_{22} y_{0}\right] \frac{t^{2}}{2} \\
+\left[\left(-\frac{1}{2} a_{2} h_{2} k_{4}+h_{2} \alpha_{22} k_{4} y_{0}+\frac{\alpha_{22} h_{2}^{3} k_{3}^{2}}{\left(h_{2}+h_{2}^{2}\right)^{2}}\right)\right] \frac{t^{3}}{3}
\end{aligned}
\end{aligned}
$$

where

$$
p_{1}=\left[\begin{array}{l}
h_{1}\left(1+h_{1}\right) k_{2}-\frac{1}{2} a_{1}(1-k) h_{1}^{2} k_{2}+h_{1} \alpha_{11} x_{0} k_{2}+\frac{1}{2} \alpha_{11} h_{1}^{3} k_{1}^{2} \\
-\frac{1}{2} \alpha_{12} h_{1} x_{0} k_{4}-\frac{1}{2}\left(\frac{\alpha_{12} h_{1}^{2} h_{2}}{\left(h_{2}+h_{2}^{2}\right)} k_{1} k_{3}+\frac{h_{1}}{2} \alpha_{12} y_{0} k_{2}\right)
\end{array}\right]
$$$$
p_{2}=\left(-\frac{1}{2} a_{2} h_{2} k_{4}+h_{2} \alpha_{22} k_{4} y_{0}+\frac{\alpha_{22} h_{2}^{3} k_{3}^{2}}{\left(h_{2}+h_{2}^{2}\right)^{2}}\right)
$$$$
k_{1}=\left[-a_{1}(1-k) x_{0}+\alpha_{11} x_{0}^{2}-\alpha_{12} x_{0} y_{0}\right]
$$

$k_{2}=\frac{h_{1} x_{0}}{2}\left[h_{1}\left(-a_{1}(1-k)+\alpha_{11} x_{0}-\alpha_{12} y_{0}\right)\left(-a_{1}(1-k)+2 \alpha_{11} x_{0}-\alpha_{12} y_{0}\right)-h_{2} \alpha_{12}\left(-a_{2} y_{0}+\alpha_{22} y_{0}^{2}\right)\right]$

$k_{3}=\left(h_{2}+h_{2}^{2}\right)\left[-a_{2} y_{0}+\alpha_{22} y_{0}^{2}\right]$

$k_{4}=\frac{h_{2}^{2} y_{0}}{2}\left[\left(a_{2}^{2}-3 a_{2} \alpha_{22} y_{0}+2 \alpha_{22}^{2} y_{0}^{2}\right)\right]$

The second order approximation to the solution will be given

$$
\begin{aligned}
& x(t) \approx x_{0}+x_{1}(t)+x_{2}(t), y(t) \approx y_{0}+y_{1}(t)+y_{2}(t) \\
& x_{1}(t) \approx x_{0}+\left[2 h_{1}+h_{1}^{2}\right] k_{1} t+l_{1} \frac{t^{2}}{2} \\
& y_{1}(t) \approx y_{0}+\left[2 h_{2}+h_{2}^{2}\right] k_{2} t+l_{2} \frac{t^{2}}{2}
\end{aligned}
$$

The third order approximation to the solution will be considered as

$$
\begin{aligned}
& x(t) \approx x_{0}+x_{1}(t)+x_{2}(t)+x_{3}(t) \\
& y(t) \approx y_{0}+y_{1}(t)+y_{2}(t)+y_{3}(t) \\
& x(t) \approx x_{0}+\left[3 h_{1}+3 h_{1}^{2}+h_{1}^{3}\right] k_{1} t+\left(l_{1}+m_{1}\right) \frac{t^{2}}{2}+\frac{t^{3}}{3} p_{1} \\
& y(t) \approx y_{0}+\left[3 h_{2}+3 h_{2}^{2}+h_{2}^{3}\right] k_{2} t+\left(l_{2}+m_{2}\right) \frac{t^{2}}{2}+\frac{t^{3}}{3} p_{2}
\end{aligned}
$$

Convergence region can be determined by using h-curves and the accuracy of the analytical solution can be improved by finding higher order approximations. Using h-curves, valid regions of a convergent series solution can be determined, by increasing the order of approximation the results are more accurate.

\section{Simulation RESULTS}

Example : $\mathrm{x}_{0}=5 ; \mathrm{y}_{0}=10 ; \mathrm{a}_{1}=5 ; \mathrm{a}_{2}=5 ; \mathrm{x}_{11}=0.10 ; \mathrm{x}_{22}=0.90 ;$ $\mathrm{x}_{12}=0.80$;

h- curves for the system of equations (2.1) via polynomial base functions

The third approximations for system (2.1) is given by

$$
L_{1}\left(x_{3}(t)-\chi_{3} x_{2}(t)\right)=h_{1}\left[\frac{d}{d t} x_{2}(t)-a_{1}(1-k) x_{2}(t)+\alpha_{11} \sum_{n=0}^{2} x_{n}(t) x_{1-n}(t)-\alpha_{12} \sum_{n=0}^{2} x_{n}(t) y_{2-n}(t)\right]
$$




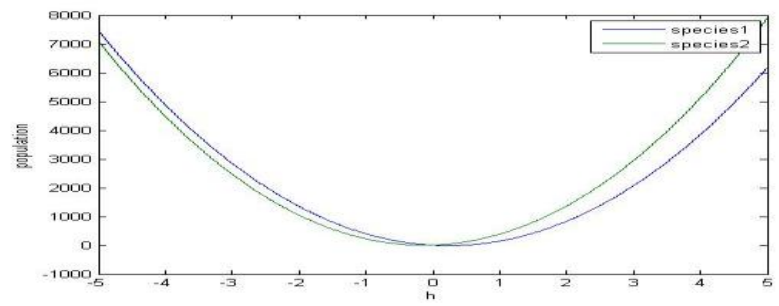

Fig. 3.1: h-curve of second order

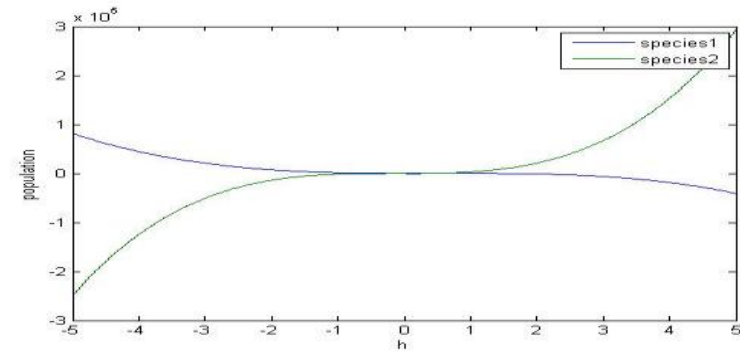

Fig. 3.2: h-curve of model third order

The Fig. 3.1 shows the h-curve of second order region of $\mathrm{h}$, is $-0.5<h<0.2$, where the series approximation solutions are convergent.

The Fig. 3.2 shows the h-curve of model (2.1) of third order approximation, the valid region of $h$, corresponding to the line segments parallel to the horizontal axis. Convergence region is $-1<h<1.2$, where the series approximation solutions are convergent.

From the above example the region of convergence is improved by third order approximation, so accuracy can be improved by increasing the order of approximations.
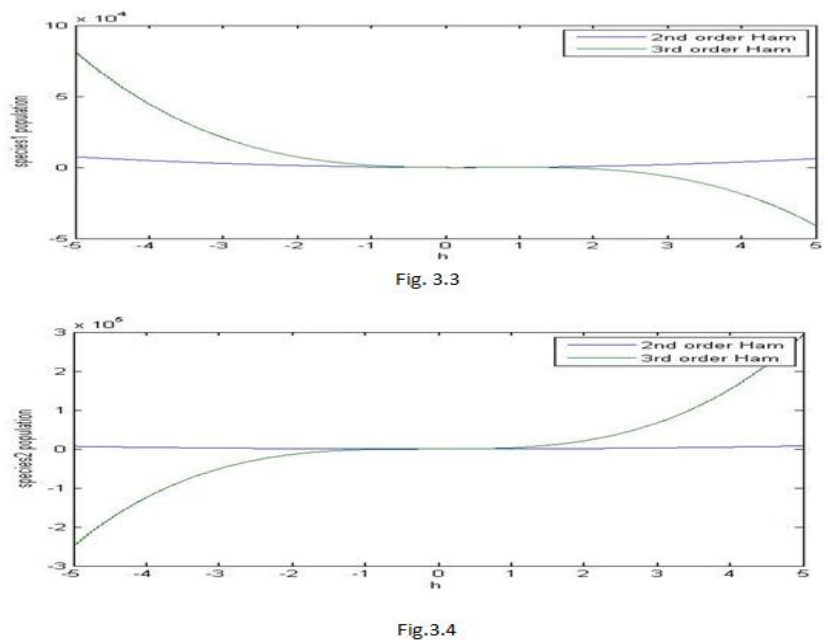

The solution curve can be obtained by fixing an auxiliary parameter ' $h$ ' for the above mentioned parametric values in example 1 .

Fig. $3.3 \& 3.4$ shows the variation of species 1 and species 2 of second and third order HAM approximations respectively.

t-curves are plotted for the above mentioned parametric values for the model (2.1) .The t-curve are population curves over time. approximation for the system of equations (2.1). The valid

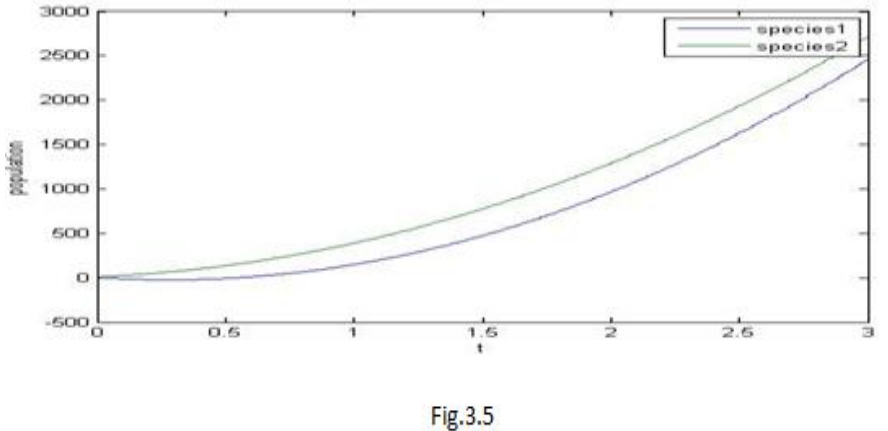

Fig. 3.5: Variation of Commensal and Species 2 with respect to time $(t)$

The Fig. 2.5.5 shows the t-curves with respect to time from the above Fig, 2.55 the initial population of species 1 increases due to commensal effect

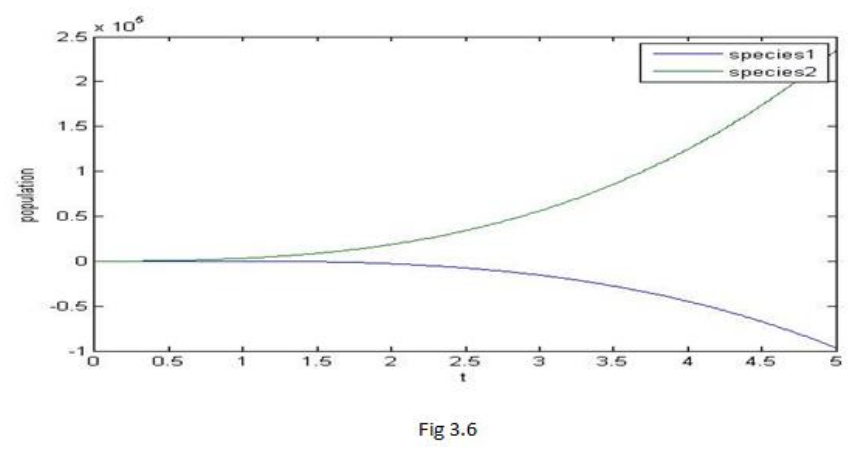

Fig. 3.6: Varition on commensal and Species with respective time $(t)$ for third order HAM solution:

From the above example it is evident that the efficiency is increased by finding higher order terms. Clearly the population of species 1 increases from the equilibrium point

\section{CONCLUSION}

In this chapter a two species commensalism model with limited resources for both the species was taken up for analytic study. The series solutions of this model are obtained by Homotopy analysis method by taking polynomial as base function. The convergence region is identified by h-curves. The solution curves of this model are discussed by t-curves. The h-curves and t-curves of Second and third order HAM series solutions are derived and found that the higher order HAM solutions are improve the efficiency of the model it clearly supported by numerical examples.

\section{REFERENCES}

1. Lotka A. J. 1925. Elements of Physical Biology, Williams and Wilking, Baltimore.

2. Voltera V, Leconseen La Theori Mathematique De La Leitte Pou Lavie, Gauthier-Villars, Paris, 1931.

3. Meyer. W. J 1925, Concepts of Mathematical Modeling, McGraw-Hill.

4. Cushing. J. N. 1977 Integro-Differential Equations and Delay Models in Population Dynamics. Lecture Notes in Bio-Mathematics. Vol. 20. Springer Verlag.

5. Kapur. J. N. 1985. Mathematical Modeling in Biology Affiliated East West.

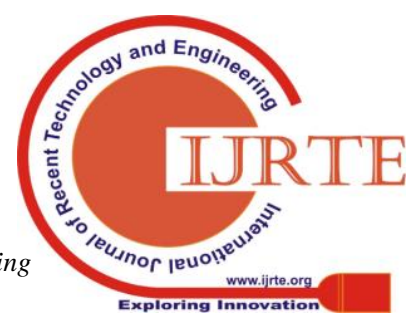


6. Kapur. J. N. 1985. Mathematical Modeling, Wiley Easter.

7. Lakshmi Narayan K., Ravindra Reddy. B. \& Pattabhiramacharyulu N.Ch., "On Global Stability of Two Mutually Interacting Species with Limited Resources for both the Species", "Int. J. of Scientific Computing", ISSN: 0973-578X, Vol.1, No.1, 2007 pp. 7-14.

8. Lakshmi Narayan K., Pattabhiramacharyulu N.Ch., "A Prey Predator Model with cover for Prey and an Alternative Food for the Predator and Time Delay", "Int. J. of Scientific Computing", ISSN: 0973-578X, Vol.1, No.1, 2007 pp. 7-14

9. Papa Rao A.V., Lakshmi Narayan K., "Dynamics of Prey predator and competitor model with time delay", "International Journal of Ecology\& Development" Year 2017; Int. J. Ecol. Dev.ISSN 0972-9984( Print ); ISSN 0973-7308 (Online), Volume 32, Issue No. 1 , Pp 75-86.

10. K. Shiva Reddy, Lakshmi Narayan. K. \& Pattabhi Ramacharyulu.N.Ch.; “ A Three Species Eco system consisting of A Prey And Two Predators”- International J. of Math.Sci. \& Engg.Appls. ISSN 0973-9424, Volime 4, Issue IV, (2010),pp. 129-145.

11. Lakshmi Narayan.K and Suryanarayana Evuri.;" A Mathematical Study of Time Delayed Commensallyism Model”- Journal of Advanced Research in Dynamical \& Control Systems., Volume 10. Issue 10, (2018),pp. 1897-1905.

12. Kondala Rao. K and Lakshmi Narayan. K., "Stability Analysis of a Three Species Food Chain Model with Harvesting, Journal of Mathematics and Sattistics" by Science signpost Publication (SS-Pub), Volume 3, Issue 9, Sept-2017, PP: 285-294, e-ISSN: 2411-2518, USA

13. Kondala Rao. K., Lakshmi Narayan. K., "Dynamical System of Ammensal Relationship of Humans on Plants and Birds with Time Delay", "Bulletin of Calcutta Mathematical Society", Volume-109, No-6, December 2017, pp 485-500 with ISSN: 0008-0659.

14. Kondala Rao. K., Lakshmi Narayan. K., "Dynamics Of Three Species Food Chain Model With Neutralism And Ammensalism" in "Research Journal of Science and Technology" (RJST) by A and V publications, Volume-9, Issue-3, July-September-2017, E-ISSN: 2349-2988, P-ISSN: 0975-4393, DOI : 10.5958/2349-2988, India.

15. Xiangdong Xiea, Fengde Chenb , Mengxin Heb., "Dynamic behaviors of two species amensalism model with a cover for the first species" published by J. Math. Computer Sci. 16 (2016), 395-401.

16. Liang Zhao, Bin_Qin and Xianbo Sun, “Dynamic Behavior of a Commensalism Model with Nonmonotonic Functional Response and Density-Dependent Birth Rates", published by Complexity, Volume 2018, Article ID 9862584, PP:1-6 ,https://doi.org/10.1155/2018/9862584

\section{AUTHORS PROFILE}

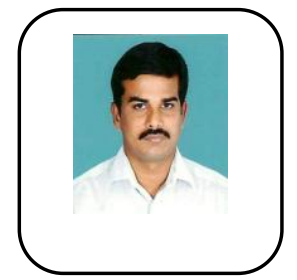

J. Govardhan Reddy completed M.Sc from Osmania University. He is pursuing Ph.D in Osmania University. He has 19 years of teaching experience. He was published 3 papers in International Journals. He attended and presented his research papers in National and International Confersnces.

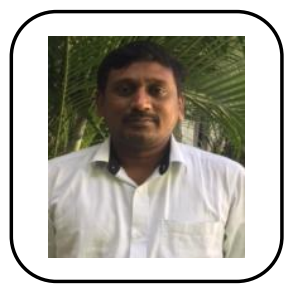

Dr. B.Sitarambabu completed his Ph.D from JNTUH, Hyderabad. He has 17 years of teaching Experience. Presently $\mathrm{He}$ is working as a Professor of Mathematics in VIDYAJYOTHI Institute of Technology, Hyderabad. He published more than 17 research articles in reputed Journals and He attended and presented more than $18 \mathrm{National} /$ International Conferences. His area of research is Mathematical Modeling like Mathematical Ecology, Epidemiology and Pharmacokinetics.

Dr. N. L. Mohna completed his Ph.D from Osmania University in Theoretical Geophysics. He got Research Fellowships from CSIR [Junior and Senior Research Fellow (1974-1978)]. He has 40 years teaching experience in Osmania University. He was farmer HOD of Dept. of Geophysics and Farmer Chairman of Board of Studies for Geophysics, Osmina University and Former coordinator \&chairman Board of studies Computational Geophysics (2009-12, OU). He was UGC Emeritus Fellow (2012-15). He was Awarded by National Mineral Award, Govt of India, Ministry of Mines and steels (1995), Gold medalist of Indian Geophysical Union (2007). He was published more than 100 papers in International and
National Journals and 6 Books (Inernational \& National). He was guided 4 Ph.D scholars (2 Geophysics \& 2 Mathematics) and he guided several PG and UG studentsin Geophysics and computersciences. He is a visiting professor of Dept. of Petroleum Engineering, University of Libya. DAAD visiting Senior Fellowship (July-Aug 1988), DAAD, Germany. 